JGG 2021;69:218-220

doi: $10.36150 / 2499-6564-N 342$
Clinical Observations in Geriatrics - Clinical experiences and Case Reports

\section{Clinical dilemma in the management of an unstable spinal fracture in a frail older patient with multiple comorbidities- conservative versus non-conservative care. A case report}

Nigil Palliyil, Rakesh Dhake, Badmus Olakunle, Elen Evans, Khalid Salem, Opinder Sahota

Queens Medical Centre, Nottingham, United Kingdom

Significant dilemma exists in literature regarding the management (surgical vs conservative) of elderly patients with significant comorbidities presenting with spinal injuries.

An 82 years old female patient with significant comorbidities and a background of ankylosing spondylitis presented with unstable fractures of the thoracic spine. Multidisciplinary team approach with medical optimisation, early surgical intervention followed by rehabilitation was offered to her. She made an uneventful recovery and returned back to her baseline mobility.

Key words: ankylosing spondylitis, unstable fracture in elderly, musculoskeletal, falls and fractures, frailty and sarcopenia

Received: January 10, 2021

Accepted: April 29, 2021

\section{Correspondence}

Nigil Palliyil

Queens Medical Centre, Derby Road NG72UH, Nottingham, United Kingdom

How to cite this article: Palliyil N, Dhake R, Olakunle B, et al. Clinical dilemma in the management of an unstable spinal fracture in a frail older patient with multiple comorbidities-conservative versus non-conservative care. A case report. Journal of Gerontology and Geriatrics 2021;69:218-220. https://doi. org/10.36150/2499-6564-N342

(C) Copyright by Società Italiana

di Gerontologia e Geriatria (SIGG)

\section{(c) (1) () $\odot$}

OPEN ACCESS

This is an open access article distributed in accordance with the CC-BY-NC-ND (Creative Commons Attribution-NonCommercial-NoDerivatives 4.0 International) license. The article can be used by giving appropriate credit and mentioning the license, but only for non-commercial purposes and only in the original version. For further information: https://creativecommons.org/licenses/by-nc-nd/4.0/deed.en

\section{INTRODUCTION}

An 82 years old female patient with known ankylosing spondylitis was transferred to the regional spine unit with an unwitnessed fall. She had a significant past medical history of Alzheimer's dementia, chronic kidney disease (stage 3), bronchial asthma and scored 7 out of 9 on the Rockwood Clinical Frailty Score. She had sustained an unstable neck injury two years ago, which was managed conservatively as she was deemed to be high risk/unfit for surgery.

She lived alone with carers four times a day and was able to mobilise independently with a frame indoors. The CT scan of her spine revealed unstable fractures at T5-6 and T11-12 levels with translation of the spinal column at T5-6. Managing her with a brace this time around would have been practically impossible because of the nature of the fractures, the number of levels involved and the potential risk of cord injury with further translation of the spinal column. Her case was discussed in the multidisciplinary (MDT) meeting comprising of the spinal surgeons, ortho-geriatrician, anaesthetist, intensivist and patients' relatives (who had lasting power of attorney). It was decided that surgical stabilisation was the best possible option for her after medical ortho-geriatric optimisation, with the proviso that critical care bed would not be offered to her post-operatively. Following the discussion with the anaesthetist, it was decided that the surgery should be done in the shortest possible time duration, as she was 

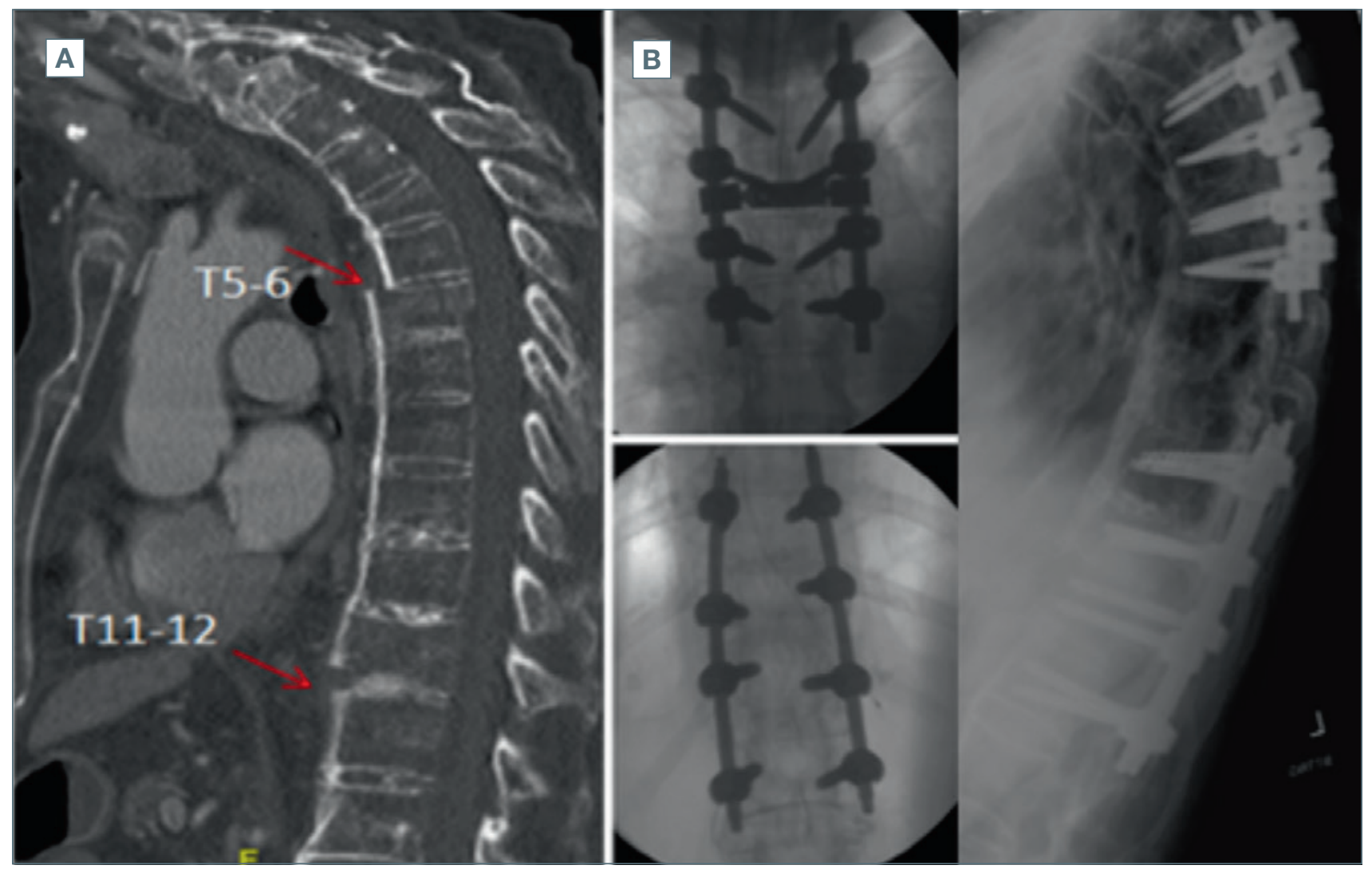

Figure 1. A) preoperative CT scan showing unstable spinal fractures at T5-6 and T11-12; B) postoperative radiographs showing posterior stabilization of fractures at both levels.

unlikely to tolerate prolonged anaesthesia. It was decided to operate her T5-6 facture as a priority as it was more unstable, and to proceed to the lower level based on how well she tolerated the first half of the procedure. She underwent T4-7 open posterior stabilisation along with minimally invasive T10-L1 posterior stabilisation with pedicle screws and rods (Fig. 1). Minimally invasive procedure could not be used for the upper levels due to inadequate visualisation on the lateral flouroscopy and in view of significant translation of spinal column at that level. The surgical duration was 2.5 hours and the blood loss was around $400 \mathrm{mls}$. Postoperatively, she had significant improvement in her pain scores. She was able to sit out for her meals within 24 hours after surgery, and at 36 hours able to mobilise a few steps. Her catheter was removed at 48 hours and able to mobilise to the toilet by day 5 .

\section{DISCUSSION}

Patients with AS are at high risk for spinal fracture when compared to the general population due to their stiff spine with long lever arms and underlying osteoporosis ${ }^{1}$. Cervical spine is the most commonly involved level. CT scanning of the entire spine is essential in these cases as many of the occult fractures can be missed in plain radiographs and MRI imaging ?

Conservative management of these fractures is associated with significant problems including skin ulcerations, chest infections, delirium and loss of muscle mass due to a prolonged immobilization with brace ${ }^{3}$, however the risk of surgical intervention also remain high.

Multidisciplinary team approach with medical optimisation, early surgical intervention followed by rehabilitation is considered the ideal treatment for older people with significant spinal injuries. Ortho-geriatric care has emerged as a collaborative care model between geriatricians and orthopaedic surgeons for older adults hospitalised with hip fracture ${ }^{4}$. A national survey has shown that increasing ortho-geriatrician time spent per patient from 1.5 to 4 hours, resulted in reduction in time to theatre, with an overall 3.4\% decrease in 30day mortality ${ }^{5}$. Since the inception of ortho-geriatric care, most of the published research in this field has examined its application to patients with a hip fracture, which is unsurprising given that hip fractures cause significant morbidity and mortality, along with substantial 
healthcare costs. However, spinal fragility fractures are common in older people admitted to hospital and we have shown that collaborative involvement between ortho-geriatricians and spine surgeons may also lead to an improvement in patient outcomes.

\section{Ethical consideration}

None.

\section{Acknowledgement}

None.

\section{Funding}

None.

\section{Conflict of interest}

The Authors declare no conflict of interest.

\section{Author contributions}

All the authors contributed in the development of this manuscript.

\section{References}

1 Lukasiewicz AM, Bohl DD, Varthi AG, et al. Spinal fracture in patients with ankylosing spondylitis: cohort definition, distribution of injuries, and hospital outcomes. Spine 2016;41:191-196. https://doi.org/10.1097/ BRS.0000000000001190

2 Harrop JS, Sharan A, Anderson G, et al. Failure of standard imaging to detect a cervical fracture in a patient with ankylosing spondylitis. Spine 2005;30:e417-e419. https:// doi.org/10.1097/01.brs.0000170594.45021.67

3 Alaranta H, Luoto S, Konttinen YT. Traumatic spinal cord injury as a complication to ankylosing spondylitis. An extended report. Clin Exp Rheumatol 2002;20:66-68.

4 Middleton $\mathrm{M}$. Orthogeriatrics and hip fracture care in the UK: factors driving change to more integrated models of care. Geriatrics (Basel) 2018;3:55. https://doi. org/10.3390/geriatrics3030055

5 Neuburger J, Currie C, Wakeman R, et al. Increased orthogeriatrician involvement in hip fracture care and its impact on mortality in England. Age Ageing 2017;46:187-192. https://doi.org/10.1093/ageing/afw201 